\title{
Construction of the Professional Quality Evaluation System of Environmental Impact Assessment Engineers Based on Yaahp Software
}

\author{
Liu Yan* \\ Xingzhi College of Xi'an University of Finance and Economics, Xi'an Shaanxi 710038
}

\begin{abstract}
Improving the evaluation index system for environmental impact assessment engineers is one of the important tasks in the current environmental protection talent training. According to the basic requirements of the professional qualification examination for environmental impact assessment engineers, the professional quality evaluation index system of environmental impact assessment engineers has been constructed from three levels of basic requirements, relevant knowledge and practical skills, and the index weight set is established through Yaahp software, with the aim of being an environmental protection talent The construction of the evaluation system provides thinking.
\end{abstract}

\section{Introduction}

In 2003, the State Environmental Protection Administration issued "Several Opinions on Strengthening the Construction of the National Environmental Protection System Talent Team", which greatly improved the overall quality of the environmental protection system talent team's political thinking, professional ethics, and knowledge level, and built a sufficient number and reasonable structure. High-quality environmental protection talent team. In 2014, the Ministry of Environmental Protection issued the "Opinions on Strengthening the Construction of Grassroots Environmental Protection Talents", which pointed out that it should increase the exchange and training of grassroots environmental protection talents, improve the effect of grassroots environmental protection talent education and training, improve the structure of the grassroots environmental protection talent team and evaluate and encourage work, and strive to create a good policy Environment, give full play to the enthusiasm of mobilizing various forces to participate in environmental protection talents. In 2016, the National Development and Reform Commission, the Ministry of Science and Technology, the Ministry of Industry and Information Technology, and the Ministry of Environmental Protection jointly issued the "Thirteenth Five-Year" Energy Conservation and Environmental Protection Industry Development Plan to consolidate the talent base, strengthen professional skills training, strengthen environmental protection team capacity building, and improve personnel Business quality. From a policy perspective, the national and social requirements for the talent structure and quality level of environmental impact assessment continue to increase. Professionalization of literacy, professional skills and management standardization are the development goals and trends of environmental impact assessment engineers.

\section{Literature review}

Professional literacy is the comprehensive quality of ideological and moral level, professional theoretical knowledge, and business skills that people need to have in a certain occupation in a specific working environment. It is the inherent requirement and norm of the occupation. With the promulgation of the "Environmental Impact Assessment Law of the People's Republic of China" in 2002 and the implementation of the professional qualification system for environmental impact assessment engineers in 2004, environmental impact assessment engineers have received more and more attention from the society, and higher requirements have been placed on environmental impact talents. Chinese scholars have analyzed and discussed the ability and quality of environmental impact assessment engineers. Dayong Tian,Yong Zheng, Dong Yan[1] point out that environmental impact assessment work is still a new thing in our country. Pay attention to the cultivation of practical ability. Yuanfen Yin[2] points out that the professional role of environmental impact assessment engineers determines their ethical responsibility for the environment, which includes environmental safety responsibility, sustainable development responsibility and ecological justice responsibility. Jinling Chen[3] points out that the quality of EIA staff needs to be improved, and most of them lack practical experience, which leads to their poor judgment on environmental impacts, and they are obviously insufficient in grasping. Weijun Zhao[4] urgently needs environmental protection practitioners to

\footnotetext{
*Corresponding author: lyxingzhi1985@163.com
} 
consciously keep to the bottom line of the legal system and ethics, regulate their professional behavior, improve their ideological and moral quality, scientific and cultural quality, and technical and professional quality, and cultivate their professional ethics and professionalism. Create a good atmosphere of integrity. Jin Liu, etc.[5] pays attention to the ability training of environmental majors. Wenlan Yang, ect.[6] carry out engineering education certification can effectively promote professional construction, improve the quality of talent training, and enhance the industry adaptability and recognition of talents. To sum up, although the professional quality of environmental impact assessment engineers in China has a certain research foundation, it is mainly based on perceptual knowledge, and more concentrated on the training of environmental impact assessment talents in colleges and universities, and the construction of environmental impact assessment courses. The professional quality ability of environmental impact assessment engineers lacks relatively systematic analysis and evaluation.

Based on the discussion and analysis of the above literature, this article intends to build an environmental impact assessment engineer's professional quality evaluation system and decompose its index weight with the aid of Yaahp software, hoping to provide a reference for the quality assessment and mechanism construction of environmental impact assessment talent training.

\section{Construction standards for the professional quality evaluation system of environmental impact assessment engineers}

\subsection{Accuracy standards}

The meaning of the evaluation indicators and the information conveyed by the professional quality of environmental impact assessment engineers must be clear, and can be accurately linked to professional qualifications, so that people can judge what evaluation indicators are expected by the environmental impact assessment organization, and accuracy also means the index system covers the content of the actual work process to the greatest extent. The National Professional Qualifications Provisional Regulation "Environmental Impact Assessment Engineer" promulgated in 2004 puts forward assessment requirements for the professional standards, knowledge, skills, and ethics of environmental impact assessment personnel. Therefore, the evaluation index system follows the content of professional qualification standards and links the index system with the professional qualification certification system. Although the professional access qualification standards have problems such as insufficient standards, it can still be used for the construction of the professional quality evaluation system of environmental impact assessors.
The professional quality evaluation index system of environmental impact assessment engineers serves practice. It is necessary to consider the operability of the implementation process and the relationship between implementation costs and benefits. In reality, many evaluation index systems are highly scientific, but due to the implementation cost is too high, it is not economically cost-effective and has to be put on the shelf. Therefore, reasonable application is a very important aspect in the construction of the index system.

\subsection{The unified standard of theory and practice}

The determination of indicators includes not only the professional knowledge to be mastered, but also the practical skills to achieve the unity of theory and practice. Under the concept of "ecology revitalizes civilization" and "green water and green mountains are golden mountains and silver mountains", EIA personnel should not only possess traditional theories and knowledge, but also master scientific evaluation methods and methods, such as big data analysis, informatization, etc. , And should have the ability to analyze and make decisions, and be able to independently complete the entire chain of management and control of EIA cases from planning to completion.

\section{Construction process of environmental impact assessment engineer's professional quality evaluation system}

In this paper, Yaahp analysis software is used to provide assistance in many aspects such as model construction, judgment matrix input, judgment matrix consistency correction, weight ordering, etc., saving a lot of calculation steps and time.

\subsection{Determine the index system}

The assessment standards of "Environmental Impact Assessment Engineer" are divided into knowledge and skills, including "Environmental Impact Assessment Relevant Laws and Regulations", "Environmental Impact Assessment Technical Guidelines and Standards", "Environmental Impact Assessment Technical Methods", "Environmental Impact Assessment" "Case Analysis" four examination modules, environmental impact assessment engineers can register according to 16 registration categories. According to the entry standards of "Environmental Impact Assessment Engineers" and combined with the actual situation, this article intends to divide the professional quality evaluation system of environmental impact assessment engineers into three levels: general objectives, first-level indicators, and second-level indicators. The first-level indicators include Basic requirements, relevant knowledge and technical and practical skills indicators, the secondary indicators contain 9 specific elements (Table 1).

\subsection{Reasonability standard}


Table 1. Evaluation Index System of Professional Quality of Environmental Impact Assessment Engineers

\begin{tabular}{|c|c|c|c|}
\hline Aim & $\begin{array}{l}\text { First level } \\
\text { indicator }\end{array}$ & Secondary indicators & instruction \\
\hline & Basic & Professional ethics & $\begin{array}{l}\text { Professional ethics, environmental protection awareness, } \\
\text { environmental protection responsibility }\end{array}$ \\
\hline & Requirements & Social responsibility & $\begin{array}{l}\text { Maintain environmental safety, promote sustainable } \\
\text { development, and promote ecological justice }\end{array}$ \\
\hline & & Laws and regulations & Environmental protection laws and regulations \\
\hline $\begin{array}{l}\text { Environmental } \\
\text { impact }\end{array}$ & $\begin{array}{l}\text { Knowledge } \\
\text { and }\end{array}$ & $\begin{array}{l}\text { Technical guidelines } \\
\text { and standards }\end{array}$ & $\begin{array}{l}\text { The complexity of the environment and the diversification of } \\
\text { the types of construction projects require environmental } \\
\text { impact assessment engineers to follow technical guidelines } \\
\text { and standards, and explore the relationship between these } \\
\text { complexity and diversity }\end{array}$ \\
\hline $\begin{array}{l}\text { assessment } \\
\text { and protection }\end{array}$ & & $\begin{array}{l}\text { Evaluation method } \\
\text { technology }\end{array}$ & $\begin{array}{c}\text { Continuously learn new methods and new technologies for } \\
\text { environmental impact assessment }\end{array}$ \\
\hline $\begin{array}{c}\text { personnel } \\
\text { occupational }\end{array}$ & & $\begin{array}{l}\text { Environmental } \\
\text { protection expertise }\end{array}$ & $\begin{array}{l}\text { Professional theoretical knowledge related to environmental } \\
\qquad \text { protection }\end{array}$ \\
\hline $\begin{array}{c}\text { quality } \\
\text { evaluation }\end{array}$ & & $\begin{array}{l}\text { Data analysis and } \\
\text { planning }\end{array}$ & $\begin{array}{l}\text { Realize data analysis and overall planning with the help of } \\
\text { data analysis software }\end{array}$ \\
\hline system & $\begin{array}{l}\text { Practical } \\
\text { Skills }\end{array}$ & $\begin{array}{l}\text { collect and analyze } \\
\text { data }\end{array}$ & $\begin{array}{l}\text { Environmental impact assessment engineers need to do their } \\
\text { utmost to collect the construction project's own situation, } \\
\text { social environment, public or group opinions, etc., as } \\
\text { complete as possible, and use the collected data for analysis, } \\
\text { processing and sorting. }\end{array}$ \\
\hline & & $\begin{array}{l}\text { Environmental impact } \\
\text { assessment document } \\
\text { preparation } \\
\text { technology }\end{array}$ & $\begin{array}{l}\text { The environmental impact assessment engineer should not } \\
\text { only make the preparation of the assessment report concise, } \\
\text { but also make it accurate. }\end{array}$ \\
\hline
\end{tabular}

\subsection{Establish a hierarchical structure model}

Divide the hierarchical structure and build a hierarchical structure model. The target layer: the professional quality evaluation of environmental impact assessment protection personnel $(Z)$; the criterion layer $(X)$ is the first-level index $\left(X_{I^{-}-X_{3}}\right)$, basic requirements, knowledge, technology, and practical skills, The index

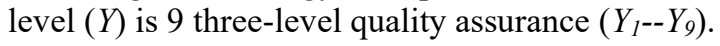

\subsection{Comparison scale}

When the Yaahp software performs weight analysis, when comparing the importance of indicators, refer to the comparison scale established by Thomas L. Saaty, using the 1-9 scale method, as shown below:

Scale 1: Same importance, which means that two indicators are equally important;

Scale 3: Slightly important, comparing the two indicators indicates that the former is slightly more important than the latter; 
Scale 5: more important, comparing the two indicators shows that the former is more important than the latter; Scale 7: Very important. A comparison of the two indicators shows that the former is more important than the latter;

Scale 9: Absolutely important. Comparison of the two indicators indicates that the former is more important than the latter;

Scales 2, 4, 6, 8 indicate that the importance of the two indicators is between adjacent judgments.

The meaning of the reciprocal of the above scale can be understood from the opposite perspective. If the importance of index $i$ compared with index $j$ is 2 , then index $j$ is $1 / 2$ compared to index $j$.

\subsection{Construct a judgment matrix to determine the index weight}

The construction of the judgment matrix is the key to determining the weight of the indicators. Refer to the evaluation standard of "Environmental Impact Assessment Engineer", and use the 9-scale method of Professor TL Saaty to determine the relative importance of each evaluation index. The evaluation indicators of the same level are paired For comparison, assign values according to relative importance. The judgment matrix of the first-level indicators is shown in Figure 1, and the assignment of the second-level indicators is the same. The results of the judgment matrix are shown in Figure 2, Figure 3 and Figure 4.

\title{
Consistency ratio: 0.0176
}

\author{
In the context of \\ al impact assessment and protection... \\ Pairwise comparisons
}

\begin{tabular}{|l|l|l|l|}
\hline & Basic Requirements & Knowledge and Technology & Practical Skill \\
\hline Basic Requirements & & $1 / 3$ & $1 / 4$ \\
\hline Knowledge and Technology & & & $1 / 2$ \\
\hline Practical Skill & & & \\
\hline & & & \\
\hline
\end{tabular}

Fig. 1. Judgment matrix of first-level indicators

\section{Basic requirements (consistency ratio: 0.0000 )}

\begin{tabular}{|l|l|l|l|}
\hline \multicolumn{1}{l}{ Basic Requirements } & Basic Requirements & Knowledge and Technology & Practical Skill \\
\hline Knowledge and Technology & & $1 / 3$ & $1 / 4$ \\
\hline Practical Skill & & & $1 / 2$ \\
\hline
\end{tabular}

Fig. 2. Judgment matrix of Basic requirement index of secondary indicators

\section{Knowledge and technology (consistency ratio: 0.0806 )}

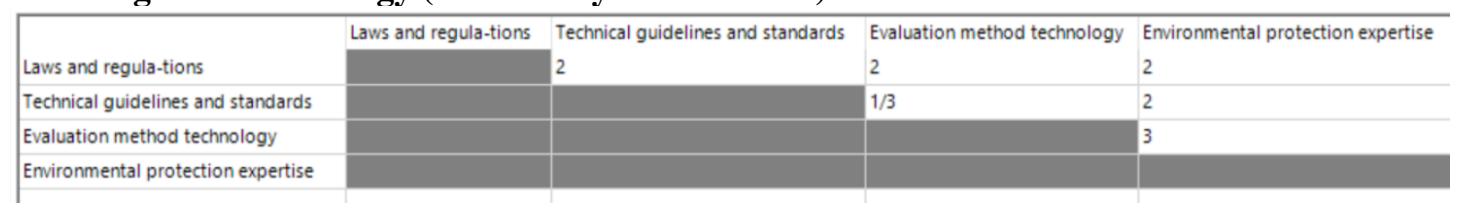

Fig. 3. Judgment matrix of knowledge and technology index of secondary indicators

Practice skills (consistency ratio: 0.0707 )

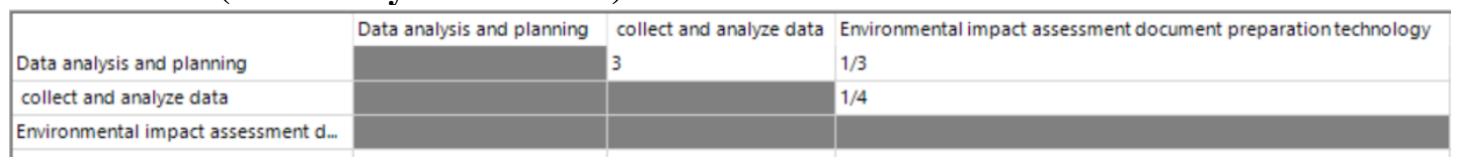

Fig. 4. Judgment matrix for Practice skills of secondary indicators 
In the analytic hierarchy process, $\mathrm{CR}$ is used as an index to test the consistency of the judgment matrix. A $\mathrm{CR}$ less than 0.1 indicates that the judgment matrix meets the consistency standard. In Figure 1, Figure 2, Figure 3 and Figure 4, the consistency ratio of the judgment matrix analyzed by Yaahp software is less than 0.1 , which meets the consistency ratio requirement. The final output index weights at all levels are shown in Figure 5.

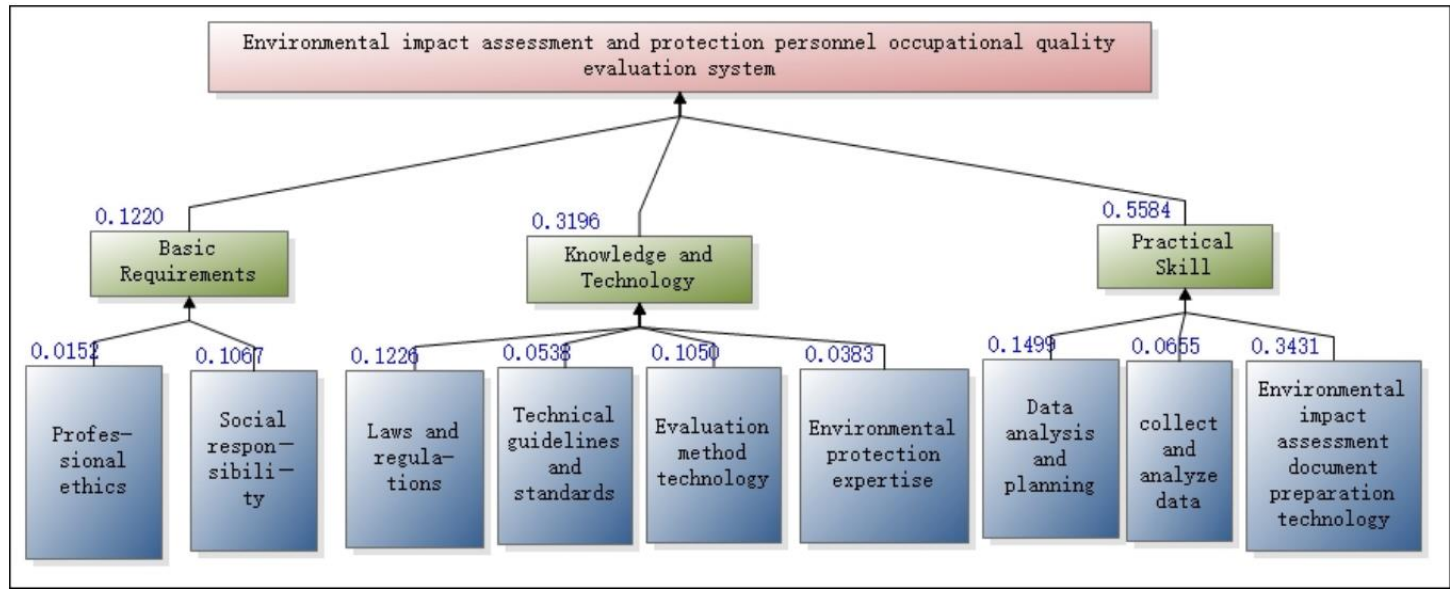

Fig. 5. Environmental impact assessment and protection personnel occupational quality evaluation index weight

\section{Conclusion}

This paper uses Yaahp software to analyze the professional quality evaluation system of environmental impact assessment engineers in a vague hierarchy, and successfully completes the decomposition of index weights. The evaluation of the professional quality of environmental impact assessment engineers is simple and practical. Future research can also use questionnaire surveys, in-depth interviews, expert scoring and other methods to further conduct in-depth research on the content and evaluation methods of the professional quality of environmental impact assessment engineers to improve the evaluation system the objectivity and scientificity.

A reasonable personnel training evaluation system is an important part of the development of services and ecological environment protection. The professional quality evaluation system of environmental impact assessment engineers can be applied to the construction of evaluation mechanisms such as the evaluation of the personnel training effect of the environmental impact assessment personnel, the performance evaluation of the position, the professional qualification certification and the performance evaluation. in. For example, in the process of training EIA talents, the curriculum design can be optimized in accordance with the requirements of professionalism to effectively improve the professional competence of EIA personnel. Second, establish a tracking and long-term feedback mechanism, conduct surveys of trainees participating in environmental impact assessment engineers, and improve the evaluation index system based on the OBE result-oriented concept. Eco-environmental protection is related to the livelihood and welfare of generation after generation. As an environmental impact assessment engineer in the new era, he must keep up with the pace of the times, be full of enthusiasm, and complete every environmental assessment work with informatization and scientific technology. Take up the responsibility given by the times.

\section{References}

1. Dayong Tian,Yong Zheng, Dong Yan. The Educational Reform of Environmental Impact Assessment under the Talent Training Model of Applied Undergraduate[J].Journal of Anyang Institute of Technology,2014,13(04):89-92+102.

2. Yuanfen Yin. Research on the Ethical Responsibility of Environmental Impact Assessment Engineers in China[D].Kunming University of Science and Technology,2015.

3. Jinling Chen.Problems and Countermeasures of Environmental Impact Assessment at Present[J].Green Environmental Protection Building Materials,2017(08):231.

4. Weijun Zhao. Inherit Development, Develop and Innovate, Open Up a New Chapter of Environmental Evaluation[J].Environment and Development,2019,31(01):4-5.

5. Jin Liu,Hongguang Ge,Fengmin Song,Zhifeng Liu,Zuoping Zhao. Teaching Reform of Environmental Quality Assessment Focusing on Ability Training[J].Guangdong Chemical Industry,2020,47(01):151-152.

6. Wenlan Yang,Jin Yin,Rongping Ji,Tianzhu Zheng,Haibing Cong. Teaching Reform of Industrial Wastewater Treatment Course Based on Engineering Education Professional Certification[J].Shandong Industry,2019,48(22):236-237. 